\title{
Языковая проекция обратного культурного шока
}

\section{Language Projection of the Cultural Shock}

\author{
Михаэла Пешкова - Галина Николаевна Божкова \\ (Пльзень, Чехия - Елабуга, Россия)
}

\begin{abstract}
:
This study analyses the diary notes of Russian studenst as the source of the language projection of the reverse cultural shock. It notes typical and significant lexemes, stylistic and grammatical structures that reflect individual phases of cultural shock as a mental process. He also observes the texts from an intercultural and imagological point of view, summarizes the Czech and Russian auto and heteroimages. Based on the linguistic analysis the author arrives at the conclusion that experiencing of cultural shock, perception of foreign and own culture is highly interpersonal phenomenon.
\end{abstract}

\section{Key words:}

cultural shock; image of Russian; image of Czech; imagology; cognitive linguistic 
Культурный шок - это широко известный психический феномен, который проявляется во время пребывания человека в другой стране и знакомства с иной культурой, а также после возвращения в родную среду. Это долговременная ситуация, состоящая из нескольких этапов: 1) фаза «медовых недель»- время, сопровождающееся эйфорией и очарованием; 2) фаза кризиса, связанная с разочарованием, беспомощностью, беспокойством, удивлением, одиночеством; 3) фаза примирения с постепенно возвращающимся ощущением уверенности и удовлетворения; 4) фаза адаптации, которая приводит к принятию новой среды [OBERG 1960], а после возвращения в родную страну человек переживает финальный этап культурного шока - момент переосмысления, анализа другой страны, он менее интенсивный, чем шок, который переживает путешественник после первичного знакомства с иной культурой.

Цель работы: пронаблюдать протекание этапов обратного культурного шока у российских студентов-стажёров, для этого преподавателями двух вузов (Западно-чешского университета и Елабужского института КФУ) были подготовлены дневники, которые студенты вели ежедневно в течение одной недели, вернувшись из чужой страны. Аутентичные первичные тексты были проанализированы тремя способами: 1) психологический - описание индивидуального внутреннего состояния; 2) культурный - указание на сходства или различия специфических культурных кодов (русско-чешское сравнение) и на общие межкультурные явления (межкультурная ситуация, типология культур, сам культурный шок); 3) информативный - рассказ о впечатлениях как источник информации о формировании «авто» и «гетеро» имиджей в широком имагологическом контексте. В первую очередь нас интересует трансформация «автоимиджа», в нашем случае русского, т.е. изменения перспективы восприятия самого себя после приобретения личного опыта пребывания в другой, в нашем случае чешской, культуре. Поэтому для исследования было выбрано именно то время, в которое респонденты погружены в обратный культурный шок, или же проходят через процесс реадаптации. Анализ конкретного текстового материала также основан на когнитивной лингвистике (тематическая область: образ общества, себя и другого в языке) [VAŇKOVÁ 2007, 41].

В декабре 2018 года преподавателями двух вузов было проведено наблюдение в качестве размером небольшого тематического исследования (case study), связанное с изучением культурного шока у восьми студентов-стажёров из Татарстана (г.Елабуга). Все респонденты впервые остались в Чешской Республике, некоторые никогда не были за границей. После трёхмесячного пребывания в Университете Западной Богемии (Чехия, Пльзень), в течение недели стажёры ежедневно записывали свои ощущения от чужой страны. 
Метод интроспективного дневника позволяет контролировать спонтанное и индивидуальное выражение языка, свободную демонстрацию чувств и размышлений, поэтому он используется в качестве эффективного средства качественного типа исследования как в психологии ${ }^{1}$, так и в лингводидактике ${ }^{2}$. В то же время, это эффективный дидактический метод для респондентов: записывая свой опыт, ученик (ца) поднимается над ситуацией, освобождается от непонимания, правильно анализирует происходящее, увлекается самим процессом записи. В противном случае полученный опыт мог бы остаться незамеченным или пережит слишком эмоционально.

Прежде всего, дневниковые записи свидетельствуют о поэтапном протекании культурного шока, что также отражается на языковой проекции. Удивительно, но все респонденты пропустили первую стадию («медовую») культурного шока и сразу пережили фазу кризиса, судя по дневниковым впечатлениям, обучающиеся испытали сильный стресс и дискомфорт: «Очень сильно грустил и унывал...». Хотя никто не использовал термин «шок» напрямую, переживание было явно идентифицировано как крайнее психическое «состояние»: мрачное, ужасное, отвратительное, депрессивное. В начале стажировки наступило полное отчуждение, фаза кризиса связана с путаницей, потерей уверенности в себе - это своего рода регресс развития: «Чувствую себя снова, как на первом курсе». На самом деле, атрибуты стресса возникают ещё и потому, что большую роль играет смена климата, тяжелый перелет, время суток, месяц: «.. вечер, зима, метель и мороз. Погода за окном вовсе пугала, было очень трудно свыкнуться». Респонденты отметили, что они психологически оставались в другой стране как после приезда в Чехию, так и после возвращения в Татарстан: «Сквозь сон сльишал, что в другой комнате кто-то ходит, первая мысль - это уборщица номеров пришла [...] нам же улетать сегодня [...] Все мысли были о том, что буквально вчера прогуливалась

1 Интроспекция является психологическим методом наблюдения за самым собой. Это наблюдение и запись собственного восприятия, мышления и переживания. Дело заключается в тщательном исследовании своего личного опыта [HARTL, HARTLOVÁ 2009, 240]. Посредством интроспекции заранее ознакомленный с данным методом респондент следит за своими умственным процессами, эмоциями, содержанием сознания и вербально их описывает Данный метод приносит ценную информацию, однако он невыгоден в том, что приобретенная информация субъективна и трудно ее проверить. Она ограничена: доступно только то, что сам человек осознает [PRŮCHA, WALTEROVÁ, MAREŠ 2003, 93]. C другой стороны, несмотря на аутентичность записей, точки зрения, которые в них выражены, могут быть не настоящими, а подверженными стилизации.

2 Это прежде всего касается использования автобиографических записей сознательно описывающий процесс обучения иностранным языкам. «Использование методов интроспекции тесно связано с изменением парадигмы: с когнитивных на социокультурные теории приобретения данных». [JANÍKOVÁ 2018]. 
по улицам Чехии [...] Просыпаясь, мне казалось, что я всё ещё в номере гостиницы, лишь позже приходило осознание того, что уже дома» - эта часть культурного шока началась задолго до отъезда. Возвращение в домашнюю обстановку связано с окончанием определенной личной свободы, пережитой в другом месте, это показательно выражается с помощью лингвистического повтора «обратно»: «Хотелось обратно [...] Желание вернуться обратно только возросло». Чрезвычайная ситуация («выход из строя») подошла к концу, и привычная жизнь вернулась со старыми проблемами и обязательствами - студенты четко вербализировали этот феномен, создавая пары оппозиций из семантического поля: «расслабление», «отдых», «спокойствие»- «гравитация», «беспокойство», «долг», «работа», «напряженность», или предложения: «В Чехии научился отдыхать душой и телом [...] Размеренная жизнь [...] На парах в Чехии мы много шутили и смеялись [...]», противопоставлены - «Голова шла кругом от нагрузки после возвращения[...] Ритм: учеба-работа-учеба».

Человек явно поглощен состоянием культурного шока, что также отражается в стилистическом аспекте текстов. Респонденты в высказываниях абсолютизируют, обобщают, гиперболизируют, чрезмерно сравнивают и показывают контрасты: «Дома все оказалось таким серым и скудным [...] Условия проживания в Чехии и России кардинально отличаются...». Перепады настроения свидетельствуют об экспрессивности, что отражено в лексике студенческих записей: «Безумно радовались; невероятно соскучился; жутко не хватало»; в грамматических категориях: наличие превосходной степени прилагательных: «чувствовала себя самой счастливой [...] снова почувствовал себя одиноко и самым несчастным человеком [...]».

Физическая усталость, недомогание («Ужасно болела голова») утихли быстро, поэтому в дневниках стали появляться фазы восстановления. Примечания доказывают, что студенты, несомненно, испытали переходный этап, связанный с «приобретением опыта». Этот тип инициации остается действительным в своей архетипической структуре: выход из дома - приключения, искушения, испытания, получение опыта [MELETINSKIJ 1989, 323]: «Трудности лишь закаляют и делают сильнее». Преобразование лингвистически проецируется в антонимах, означающих старый (до стажировки) и новый (после стажировки) миры. Записи принимают футуристический вектор: «Вспомнил о жизни до поездки. В Чехии я привык жить в комфорте и удобстве, поэтому в общежитии я жить не захотел, решил снимать квартиру [...] что-либо делать полезного, развиваться, искать себя в чем-то новом. Всю эту энергию, этот заряд, дали чехи [...] Много поставил для себя целей [...] Постоянно хочется развиваться...». После культурного обогащения в Европе можно заметить и такие фразы: «Сразу начала учить онлайн чешский язык [...] Ведь чтобы изменить мир, нужно начать 
с себя [...] Вновь отправится на стажировку [...] путешествовать. Была очень энергичной и подвижной [...] Устроился на работу [...] После культурного обогащения в Европе [...] Несмотря на все происходящие, греет мысль о том, что это всё временно, если эта плата за возможность пожить в Европе 2,5 месяца, то она того стоит - я получил хороший опыт. Моя поездка начала приносить мне пользу».

Вышеуказанное подтверждает приобретение сенсорного, эмоционального и физического опытов. Этап кризиса длился два-три дня после приезда. Исходя из этого, на первом этапе культурного шока необходимо сосредоточиться на поддержании основных умственных и физических функций организма. После этой фазы мы все чаще наблюдаем рациональные, систематические и интеллектуально более гармоничные замечания о культуре страны. Сравнение русской и чешской культур не поощрялось, но это было сделано на 100 \% без исключения, так что студенты указали на различия: «Мне было немного не привычно [...] Что меня сильно удивляет...». Никто не пытался назвать совпадения, подтверждая тенденцию к категориальному, даже биполярному восприятию реальности - феномену психологическому: человеческий разум должен помогать категоризации, а категориальный разум работает с противоположностями [ALLPORT 2004], поэтому необходимо некоторое упрощение [ERIKSEN 2012], в том числе лингвистическое. Стереотипы и прототипы обозначают «чужую» оппозицию, которая является дополнением к антропоцентризму - второму основному принципу формирования языкового образа мира» [VAŇKOVÁ 2007, 59]. Противоположности были отражены в рассмотренных текстах в семантическом противопоставлении: «наши»-«их»; «их»-«иностранные»; «здесь»-«там», «Россия»-«Чехия», и удивительно, но в паре - «Россия»-«Евроna».

На выводы респондентов определенно влияет культурный шок, поскольку замечания об иностранной культуре фиксируют прошлые события, что можно характеризовать как оптимизм памяти. Родной мир воспринимается как бессимптомный, характеризуется словами: «серыц̆», «скучный», а мир иностранной культуры считается симптоматичным, красочным, привлекательным, отличительным: «После яркой Чехии вокруг все кажется серым и невзрачным [...] серые дома, невероятная архитектура в Чехии [...] День в университете длился невероятно долго, хотя было всего 3 napbl, в Чехии 3 nары проходили на одном дыхания и этого времени не замечала».

Данный этап напоминает первую, полностью этноцентрическую фазу развития межкультурной компетенции, т. наз. поляризацию. Она принимает две формы - защиты и переворота. Человек либо воспринимает привычки своей культуры как превосходящие другую культуру и рассматривает 
культурные различия как препятствие, угрозу (оборона), либо воспринимает другую культуру как превосходящую родной (переворот) [HAMMER 2009, согласно ZERZOVÁ 2016].

Было подтверждено, что в сравнении культур нет нейтралитета; действительно, культурно обусловленная языковая картина мира «... пронизана оценкой, редко безразличной или беспристрастной» [VAŇKOVÁ 2007, 59]. Дневники не давали возможности оценить, но все студенты выражали себя по шкале «хорошо-плохо», «позитивно-негативно»: культура в Европе восхищает и мотивирует, прививает правильные манеры поведения, но многие не понимают насколько это им необходимо. Поразительно, что учащиеся утверждали вещи как факт без уверенности или сомнений и не обращали внимания на субъективность взгляда.

Некоторая культурно-специфическая информация освещена в дневниках, однако восприятие общей культуры было косвенно и интуитивно. Никто не прибегал к более осознанному экспертнальному анализу, например, согласно типологии культур [SAMOVAR, PORTER, McDANIEL, ROY 2013], и не анализировал свои впечатления, используя соответствующую терминологию. Некоторые типологические различия в культурах были названы необдуманно такими определениями, как «неформальная»-«формальная», «индивидуальныцй»-«коллективный»; «эгалитарныци»-«элитарныцй» и прочее.

Студенты естественно сравнили сферы высшего образования. Чехи ассоциируются с динамикой, практической направленностью, креативностью: «Я привыкла, что студенты на парах в Чехии больше двигаются и много практических заданий, а здесь на занятиях я в основном сидела и слушала. На занятиях мне было скучно, сухая теория и больше ничего, в Чехии мы выполняли много творческих заданий. Разгар рабочей недели, а студенты танцуют [...] Образование в России - фундаментальное и основательное».

Кроме того, стажёры отметили религиозные различия в Чехии и Татарстане: «Много вообще в России говорят о религии в отличии от Чехии - атеизм». Отличающееся отношение к патриотизму: «У нас в России любят сравнивать с другими странами, чехам обычно все равно, они себя редко с кем-то сравнивают»; алкоголю: «В России алкоголь, воспринимают негативно, в учебных учреждениях реклама спиртных запрещена. А в Чехии целые мероприятия посвящены пиву (〈Пиво с ректором〉)». С точки зрения поведения, по мнению респондентов, российское неуважение людей друг к другу контрастирует с чешской вежливостью: «... грустно-озлобленные взгляды на улице в Елабуге [...] И здесь даже удивляло первые дни, что никто не отвечает взаимно на вежливое 〈спасибо〉, 〈до свидания〉. В очереди стояли мужчины в пьяном состоянии и очень громко матерились. В Чехии я с таким не сталкивался. Однако непривычно то, 
что чехи сморкаются даже в разгар лекций». Русским студентам не понятна забота о здоровье чехов в ущерб этике.

Можно утверждать, что учащиеся демонстрировали образ русской культуры, то есть «автоимидж», в значительной степени совпадающего с общими чешскими представлениями, «гетероимиджем» ${ }^{3}:$ более высокий уровень патриотизма, религиозности, высокий уровень грубого уличного поведения. ${ }^{4}$ Образ русской зимы неуклонно проникает в эпицентр аутоизображения и гетероизображения России. Студенческие заметки указывают на то, что зима является неотъемлемой частью русской этнической идентичности («настоящзая русская зима»). Однако это не стереотип, а простой климатический факт, который бросается в глаза только по сравнению с двумя средами. Студенты демонстрируют и восприятие чешской культуры в упрощенном виде: не все чехи являются атеистами, не каждое здание имеет архитектурное качество. Иногда получается, что заключения в межкультурной области мнимые, например что касается сморкания: У людей здоровье превыше этикета. Результат обсуждения того, торопятся ли чехи меньше, чем русские (Они всё делают спокойно и развязно.), зависит не только от различия культур, а также от психологических и ситуативных факторов. ${ }^{5}$

Анализ показал, что стажировка оказала решающее влияние на изменение перспективы восприятия собственной культуры. Респонденты четко сформулировали внутреннее изменение: «Приземливиись в аэропорту Казани, почувствовал себя иностранцем, который впервые в России. На многие вещи стал смотреть иначе».

3 Основную разницу понятий образ, имидж и стереотип можно в имагологии разграничить таким образом: образ - это спонтанно созданный, внутренний продукт индивидуального восприятия другого у отдельного человека; имидж - это намеренно и искусственно созданный образ другого носивший интерперсональный характер, неотъемлемой составной частью которого является оценка и интерпретация; стереотип - это крайне устойчивый, схематический образ другого, часто сформированный на основании предрассудков (имидж и обрат народив стереотипа динамичны) [ČEPKASOV 2017, 74-75].

4 Некоторые оценочные аспекты отвечают атрибутам выявленным в других типах текстов: в медиадискурсе (чехи более вежливы, они открыто не показывают, что им надоедает работа в сфере обслуживания, не ведут себя грубо, не матерятся в обществе, не пьянствуют) [GAZDA 2017] и в чешской художественной литературе (русская эмоциональность против чешской рациональности, религиозность против атеизма, патриотизм против нигилизма) [PEŠKOVÁ 2015].

5 Необходимо учесть, что составной частью межкультурной интеракции помимо культуры являются также психические особенности индивида и конкретная ситуация (форма треугольника). От всех из них зависит понимание или непонимание собеседников [MOREE 2015, 89-90]. 
Однако воспринимать собственную культуру как иностранную неверно, с психологической точки зрения. Если чувство принадлежности к меньшинству в другой культуре также воспринималось как освобождающее, то в домашней культуре разница воспринимается как искоренение. При изменении поведения, то есть при применении норм другой культуры, респонденты сталкивались с недопониманием. Даже самый сложный студент через короткое время начинает вести себя как прежде, делая то, что ему не нравится: «Сам перестал ходить с улыбкой на лице. Начал адаптироваться: быть осторожным с людьми, становиться менее вежливым». Присоединение к большинству, кажется необходимой стратегией выживания. Следовательно, первоначальная культура не может рассматриваться в долгосрочной перспективе как поляризованная, как низшая и подвергнутая критике. В записках происходит примирение: видение переключается с довольно негативного на позитивное. Поэтому не потерять этническую идентичность очень важно для сохранения личной неприкосновенности.

Стажеры быстро, после возвращения домой, перешли в фазу примирения. Примечания содержат лексемы из семантического поля безопасности, дома, комфорта, из области духовной и материальной культуры: «День был домашним и теплым», $\kappa$ «родным домой», «у домашнего очага, родной и любимый университет, родные стены», «На кровати цельый день лежу и радуюсь, что дома».

Окончательная фаза адаптации, связанная с перестройкой поведения, наступила сразу потом. Субъективно респонденты чувствовали себя «полностью адаптированными» на шестой и седьмой день. Студенты описали эту ситуацию как радостную, лингвистически продемонстрированную, в частности, со стилистически позитивными выражениями: «Я адаптировалась полностью, такое чувство, будто бы никуда и не уезжала». «Ура! Готова, снова в форме конкурентноспособна и активна». «Забытые чувства вновь вернулись ко мне». Адаптация заключается в некотором прояснении ситуации, в автоматизации жизненного ритма: «Все стало на свои места. Нет времени, чтобы грустить и скучать. Дни становятся похожи друг на друга. Невероятно скучала по нашей русской еде, хотя и сильно полюбилась чешская кухня, но наш борш, пельмени и блинчики ничто не заменит [...] преддверие Нового года, магазины переполнены подарками, украшениями, на улицах продают елки, все это захватывает дух. Свои родные: в шапках, шубах, сильные, стрессоустойчивые, до безумия трудолюбивые, да просто - ЛЮБИМЫЕ!!!»

На этом этапе патриотизм проявляется наиболее ярко, в некоторых случаях возвращение усиливает его: «... зажечь во мне вновь тот самый огонёк, <огонёк патриотизма>. Белье поля, заснеженные леса и бескрайние просторы нашей 
Родины. Повсюду русские, которых так не хватало за границей. Люблю Россию, поняла это, уехав.». Очевидна стадия самоутверждения в собственной культуре, а также подтверждение ее «правильности», нормальности: «Влюбилась в Чехию, но поняла, что истинно русский человек!! Войдя в родные стены и увидев лица одногруппников, понял, что все-таки скучал». Родной язык способствует возникновению чувства непринужденности: «Когда я слышал русскую речь на таможне в аэропорту, мне было непривычно, но очень радостно. Безумно радовался, когда разговаривал с охранником стоянки на русском. Можно спокойно спросить у прохожего, как пройти до магазина на родном языке, а не пытаться, как в Европе, на ломанном английском-чешском объяснить местному жителю, что заблудился».

Однако нельзя не отметить субъективного убеждения стажёров в том, что культурный шок «исчез» за одну неделю, на самом деле этот процесс более длителен. После нескольких месяцев отношение слушателей к своей и чужой культуре снова меняется и пересматривается, приобретая более заметный статус: «... у многих из нас жизнь очень поменялась! В общем, нам всем очень понравилась и пошла на пользу поездка! Прекрасная Чехия, запавщая так глубоко в душу (из письма)».

Одной из дипломатических целей зарубежных стажировок может быть определенный экспорт мировоззрения принимающей культуры в культуру или сознание обучаемых. Как мы видим, эта цель не выполняется линейно, то есть стажировка не имеет прямого и непосредственного эффекта. В ходе опроса мы не обнаружили почти никакой решимости - в отличие от запланированного личностного роста - каким-то образом активно формировать и изменять внутреннюю среду под влиянием знания другой культуры: «я не буду менять порядок вещей, потому что он либо меня устраивает, либо я понимаю, ито ничто не может измениться, либо это выходит за пределы меня или просто сейчас не время [...] Однако вместо комнаты в общежитии я снял квартиру, после опыта в Чехии». Этот подход также может охарактеризовать поколение $Z$, которое относительно активно во всем мире, однако оно стоит вне идеологий и иерархий и не хочет ни во что вникать. ${ }^{6}$

Что касается целевого «выращивания друзей в Чешской Республике» посредством стажировок, это, несомненно, успешно. Студенты сигнализировали

6 Для представителей так. наз. Поколения Z (рож. 1995-2010) типичны самостоятельность, сосредоточенность, предприимчивость, подготовленность к усовершенствованию. Поколение Z - по сравнению с предыдущим Поколением Y, более реалистично и осмотрительно. Его члены стремятся найти свой индивидуальный жизненный путь, быть независимыми, организовать небольшой круг своих друзей-сотрудников избегая от иерархических структур и работы в больших компаниях [например KAZDOVÁ 2016; HORVÁTOVÁ 2016]. 
об этом эмоциональными высказываниями, лексемами, обозначающими привязанность, интернализацию, присвоение: «родная Пльзень [...] Она заняла частичку души. Чехия останется в моем сердце навсегда. Полюбившуюся Чехию [...] За что я искренне благодарен им.»

Следует подчеркнуть, что анализ дневников, с точки зрения имиджа культур и межкультурной коммуникации, имеет более обнадеживающие выводы, чем, например, исследование медийных текстов. Основную роль играет личный опыт. Прежде всего, это не показывает какой-либо существенной маркировки или принятия негативных этнических гетеростереотипов и автостереотипов из политического и медийного дискурса. Студенты в значительной степени равнодушны или априори не доверяют СМИ. Несмотря на лингвистически подчеркнутый контраст между «мы и они», он не превращается в «мы против них». Например, взаимная угроза вовсе не тематизируется. Заметки очень субъективные, потому что студенты знали, что их будут читать и исследовать. Они не содержат таких лексико-стилистических средств, как прямое разрушение, дискредитация, демонизация или напряженное обожание, сарказм, иронию, утверждение и прочие - как это обычно бывает на страницах интернет-форумов [GAZDA 2017].

Основываясь на анализе дневниковых записей, можно утверждать, что языковая проекция обратного культурного шока значительна и в некоторой степени стабильна, поэтому: 1) культурный шок воспринимается как крайне неприятное психическое состояние, отягощенное необычайной эмоциональностью. Стратегия выживания состоит в том, чтобы преодолеть этот шок и вернуться в личную зону комфорта, восстановить гармонию. Хотя это индивидуальный внутренний опыт, в его лингвистическом выражении имеется ограниченное количество лексических, стилистических, грамматических и графических средств из нескольких типичных семантических полей. Таким образом, мы можем говорить о межличностном опыте явления и его универсальной природе. На уровне языка можно четко определить различные фазы культурного шока. На первом этапе состояние шока объявляется таковым: частотное употребление таких лексемам, как «состояние», «чувство»; в фазе кризиса накапливаются выражения, связанные с бременем, одиночеством, срывом, темнотой, фраз, связывающих восстановление и перезагрузку. Примерение проявляется в лексемах, выражающих облегчение, тепло, свет и также перезагрузку. Адаптация заключается в выражении радости, принадлежности, регулярности и сдвига патриотизма. Выраженность высказываний, вначале значимых, постепенно уменьшается с адаптацией. Таким образом, цвет утверждений коррелирует с психическим состоянием, которое переживается и движется в сторону нейтралитета. 2) Культурный шок является частью долго- 
срочного межкультурного отражения взаимодействия. Первоначальная культура вновь просматривается через призму другой культуры, ее специфические признаки записываются впервые или выходят на первый план. Оказывается, что самосознание полностью кодируется в изображениях другого человека, a «гетеро» и «авто» имиджи/образы/стереотипы обуславливают друг друга. Мы можем наблюдать развитие межкультурной рефлексии, непосредственно вытекающей из фаз культурного шока: изначально резкое восприятие культурных различий, показание одной культуры, в нашем случае чужой, как лучшей (в языковом плане выделение антонимов из семантического поля свой х чужой, традиционный х новаторский, переизбыток оценочных выражений), которое постепенно сменяется реабилитацией собственной культуры (ее положительная оценка, меньше сравнительных сопоставлений, образы дома). 3) В дополнение к культурным различиям и консенсусу, важную роль в восприятии собственной и чужой культуры играют ситуационные факторы (здесь культурный шок демонстрирует степень дискомфорта или комфорта) и индивидуальная психическая установка личности. Однако представляется, что даже с учетом стандартизированного психологического и социального курса культурного шока возникают очень похожие образы чужих и самокультур, которые обычно близки к общим «гетероимиджам» и «автоимиджам». Общий дискурс имеет бо́льший вес, чем индивидуальное восприятие, или формирует его. Культурные коннотации, несомненно, являются общим, интерсубъективным и в некоторой степени общепринятым. В то же время подтверждается, что личный опыт, в нашем случае стажировка студентов за границей, снижает репликацию как гетеро, так и автостереотипов.

\section{Библиография:}

ALLPORT, G. W. (2004): O povaze předsudki̊. Praha.

ČEPKASOV, A. V. (2017): Imidž, obraz, stereotip, brenda, reputacija: schodnoje i specifičnoje. Russkij jazyk za rubežom, 2017, 5 (264), s. 74-82.

ERIKSEN, T.H. (2012): Etnicita a nacionalismus. Praha.

GAZDA, J. (2017): Obraz Čechư a Česka v ruském neoficiálním diskurzu. In: KOŁO-

DZIEJ, A., PIASECKI, T. (eds): Słowiańszczyzna dawniej i dziś - język, literatura, kultura. Monografia ze studiów slawistycznych III. Červený Kostelec, s. 101-114. HARTL, P., HARTLOVÁ, H. (2009): Psychologický slovník. Praha.

HAMMER, M.R. (2009): The Intercultural Development Inventory: An Approach for Assessing and Building Intercultural Competence. In: MOODIAN, M. A. (ed.): 
Contemporary leadership and intercultural competence: Exploring the cross-cultural dynamics within organizations. Thousand Oaks, CA, s. 203-208.

HORVÁTOVÁ, K. (2016): Generace Y je generací sití, ríká sociolog Martin Buchtík. E15.cz., 2016. Dostupné z: <https://www.e15.cz/the-student-times/generace-y-je-generacisiti-rika-sociolog-martin-buchtik-1305721>. [online]. [cit. 17. 8. 2019].

JANÍKOVÁ, V. (2018): Didaktika cizích jazyků v teorii a empirii. Přednáška. Plzeň, Západočeská univerzita, 16. 1. 2018.

KAZDOVÁ, A. (2016): Fak přilákat generace Y a Z. Práce, jídlo, peníze a vztahy. Návod na použití generací. Moderní rízení, 2016, 51 (6), s. 20-22. Dostupné z: <http://generace. forbes.cz/tabulka/>. [online]. [cit. 17. 8. 2019].

MELETINSKIJ, J. M. (1989): Poetika mýtu. Praha.

MOREE, D. (2015): Základy interkulturního soužití. Praha.

OBERG, K. (1960): Cultural Shock: Adjustment to New Cultural Environments. 1960. Dostupné z: <https://journals.sagepub.com/doi/10.1177/009182966000700405>. [online]. [cit. 29. 7. 2019].

PEŠKOVÁ, M. (2015): Hledání jiného: Obraz Ruska v současné české beletrii. In: POSPÍŠIL, I. (ed.): Aktuální problémy současné slavistiky: (jazyk - literatura kultura - politika). Brno, s. 201-208.

PRŮCHA, J., WALTEROVÁ, E., MAREŠ, J. (2003): Pedagogický slovník. Praha.

SAMOVAR, L. A., PORTER, R. E., McDANIEL, E. R., ROY, C. S. (2013): Communication between cultures. Wadsworth.

VAŇKOVÁ, I. (2007): Nádoba plná řeči. (Člověk, řeč a pririrozený svět.). Praha.

ZERZOVÁ, J. (2016): Intercultural Development Inventory®, version 3 - nástroj pro měrení rozvoje interkulturní kompetence. In: PEŠKOVÁ, M., KUBÍKOVÁ, K. (eds). Rozvíjení interkulturní komunikační kompetence ve výuce jazyků. Plzeň, s. 33-40.

\section{About the authors}

Michaela Pešková, University of West Bohemia in Pilsen, Faculty of Education, Department of Russian, Pilsen, Czech Republic, peskova@krf.zcu.cz

Galina Nikolaevna Bozhkova, Kazan University, Yelabuga Institute, Russian Language and Literature Department, Yelabuga, Russia, bozhkova.galina@mail.ru 